\title{
Strength and mobility of older adults living in urban, rural, and FELDA settlements in Malaysia
}

\author{
Maria Justine ${ }^{1,4}, \mathrm{PT}, \mathrm{PhD}$, Adha Nawawi ${ }^{1,2}, \mathrm{PT}, \mathrm{BPT}$, Azizah Ishak ${ }^{3} \mathrm{PT}, \mathrm{BPT}$
}

\begin{abstract}
Introduction. The aim of this study was to compare strength and mobility of older adults living in Malaysia and to determine whether strength is correlated with mobility.

Methods. This cross-sectional study recruited adults aged $\geq 60$ years old living in urban, rural, and Federal Land Development Authority (FELDA) settlements in Malaysia. Upper limb strength (using a handgrip dynamometer), lower limb strength (using the 30-second chair stand test), and mobility (using the timed up and go test) were evaluated for all participants.
\end{abstract}

Results. A total of 576 older adults living in urban $(n=192)$, rural $(n=101)$, and FELDA ( $\mathrm{n}=283)$ settlements were included. Mobility was correlated with upper limb strength in women living in urban settlements $(r=$ $-0.408, p=0.001)$, men living in rural settlements $(r=-0.599, p=0.003)$, and men living in FELDA settlements $(r=-0.281, p=0.006)$. Mobility was correlated with lower limb strength in women $(r=-0.686, p<0.001)$ and men $(r=-0.415, p=0.035)$ living in urban settlements, and women $(\mathrm{r}=-0.246, \mathrm{p}=0.001)$ and men $(\mathrm{r}=-0.281, \mathrm{p}=0.006)$ living in FELDA settlements.

Conclusion. It is important to establish public policies for interventional strategies for older persons at risk of functional decline specific to the uniqueness of the settlement.

Key words: Aged; Malaysia; Muscle strength; Mobility; Physical functional performance; Rural health; Urban health

\section{ORIGINAL ARTICLE}

\footnotetext{
1 Centre for Physiotherapy Studies, Faculty of Health Sciences, Universiti Teknologi MARA Selangor Branch, Puncak Alam Campus, Selangor, Malaysia

2 Physiotherapy Department, Kuala Lumpur Hospital, Kuala Lumpur Malaysia

3 Physiotherapy Services, Kluang Utama Specialist Hospital, Kluang, Johor, Malaysia

4 Clinical and Rehabilitation Exercise Research Group, Faculty of Health Sciences, Universiti Teknologi MARA, Selangor Branch, Puncak Alam Campus, Selangor, Malaysia
}

Correspondence to: Maria Justine, Centre for Physiotherapy Studies, Faculty of Health Sciences, Universiti Teknologi MARA Selangor Branch, Puncak Alam Campus, 42300 Puncak Alam, Selangor, Malaysia. Email:maria205@uitm.edu.my

\section{INTRODUCTION}

In 2018, approximately $6.5 \%$ of the 32 million population of Malaysia were aged $\geq 65$ years. ${ }^{1}$ Malaysia will soon be considered an ageing nation, when more than $7 \%$ of its population are aged $\geq 65$ years. In Malaysia, the living environment is divided into urban, rural, and Federal Land Development Authority (FELDA) settlements. The populations living in these three settlement types differ in terms of ethnicity, lifestyle, level of education, level of income, and employment type. FELDA was developed $>50$ years ago with the intention to provide agricultural land to communities so that they can earn a living by planting palm trees for palm oil products. Most of the earlier FELDA settlers are now aged $\geq 60$ years. $^{2}$

Age-related loss of muscle mass and strength has important health consequences, including predisposing older adults to functional limitations. ${ }^{3}$ Previously, sarcopenia was characterised by reduced muscle mass, reduced muscle strength, and poor mobility ${ }^{4}$; however, the definition has been recently revised. The current definition focuses on muscle strength, and uses muscle quantity and quality to confirm the diagnosis, with poor mobility indicative of severe sarcopenia. ${ }^{5}$ 
The present study aims to determine any correlations between strength and mobility in older persons living in urban, rural, and FELDA settlements in Malaysia.

\section{METHODS}

\section{Participants and study design}

This was a cross-sectional study involving adults aged $\geq 60$ years living in urban (Petaling Jaya), rural (Cerakah Jaya, Kuang, and Puncak Alam), and FELDA (Jengka Pahang and Johor) settlements. The data were gathered from 2014 to 2016 as part of a communitywide project to measure the functional fitness of older adults. Inclusion criteria were: age $\geq 60$ years, able to walk independently or with walking aid, and able to understand verbal instructions and study procedures in Malay. Exclusion criteria were: underweight $(<18.5$ $\left.\mathrm{kg} / \mathrm{m}^{2}\right)$, diagnosis of hypertension or diabetes but not on regular medication, major chronic illness (such as heart disease or stroke), recent surgery ( $<6$ months), severe visual or hearing impairment, acute illness or pain, and cognitive impairment (score $<24$ on the Mini Mental State Examination).

This study was approved by the Research Committee of the Faculty of Health Sciences, Universiti Teknologi MARA, Malaysia (Ref. No: REC/109/15). Before admission to this study, all participants were briefed on the study purpose and procedures, and provided written informed consent.

\section{Study procedures}

The blood pressure of consenting participants was taken to ensure their eligibility and fitness to participate in the study. Participant demographics and health status were then collected using a structured interview questionnaire. Upper and lower limb strength were measured. Participants were allowed to rest for 15 minutes after the strength tests, before the mobility test.

\section{Upper limb strength}

Upper limb strength was measured using a handgrip dynamometer (Jamar ${ }^{\mathrm{TM}}$ dynamometer). ${ }^{6}$ First, participants sat on a chair (seat height, $43 \mathrm{~cm}$ ) and held the handgrip dynamometer with their arm in $90^{\circ}$ flexion. Participants were then asked to squeeze the handgrip dynamometer as hard as possible for about $2 \mathrm{~s}$, and then to switch hands to avoid fatigue. Measurements were taken three times for each hand. The best score from the six attempts was used for the data analysis. ${ }^{7}$ To determine those at risk of sarcopenia, the cut-off for hand grip strength is $<22.4 \mathrm{~kg}$ for men and $<14.3 \mathrm{~kg}$ for women. ${ }^{8}$

\section{Lower limb strength}

Lower limb strength was evaluated using the 30-second chair stand test. ${ }^{9}$ First, participants sat on a chair (seat height, $43 \mathrm{~cm}$ ) with their feet resting on the floor, and hands crossed at the wrists and held to the chest. Participants were then asked to stand up and sit down again as many times as possible in 30 $\mathrm{s}$; a higher number of repetitions represents better lower limb strength; the cut-off is 15 repetitions. ${ }^{10}$

\section{Mobility}

Mobility was tested using the timed up and go test. ${ }^{11}$ First, participants sat on a chair (seat height, 43 $\mathrm{cm})$. Participants were then asked to stand up, walk straight for $3 \mathrm{~m}$ at their normal pace, turn around, return to the chair, and sit down again. To determine those at risk of sarcopenia, the cut-off time for poor mobility is $\geq 20$ s. $^{5}$

\section{Data Analysis}

Power analysis was conducted using $\mathrm{G}^{*}$ Power 3 software, ${ }^{12}$ the results of which indicated a minimum of 100 samples were required to yield a significant result. One-way analysis of variance was used to compare among the urban, rural, and FELDA settlement groups. Data were further analysed using Scheffe post hoc tests to reveal significant differences between pairs of groups. Pearson's correlations were conducted to determine correlations between upper and lower limb strength and mobility. Data were analysed using SPSS (Windows version 21; IBM Corp, Armonk [NY], US). A p value of $<0.05$ was considered significant.

\section{RESULTS}

Of 650 older adults came for the community-wide project, 576 fulfilled the inclusion criteria and were living in urban ( $\mathrm{n}=192)$, rural $(\mathrm{n}=101)$, and FELDA $(n=283)$ settlements (TABLE $\mathbf{1})$.

The three groups differed significantly in terms of age: men living in urban settlements were younger than those living in FELDA settlements (65.83 vs 68.45, $\mathrm{p}<0.001$ ); women living in urban settlements were younger than those living in rural settlements (65.92 vs 69.53, p<0.001); and women living in rural 
TABLE 1

Demographics, upper and lower limb strength, and mobility of older adults living in urban, rural, and Federal Land Development Authority (FELDA) settlements in Malaysia

\begin{tabular}{|c|c|c|c|c|c|c|c|c|c|c|}
\hline \multirow{2}{*}{$\begin{array}{l}\text { Charac- } \\
\text { teristics }\end{array}$} & \multicolumn{2}{|c|}{ Urban $(n=192)^{*}$} & \multicolumn{2}{|c|}{ Rural $(n=101)^{\star}$} & \multicolumn{2}{|c|}{ FELDA $(n=283)^{*}$} & \multicolumn{2}{|c|}{ ANOVA } & \multicolumn{2}{|c|}{ Scheffe post hoc test } \\
\hline & $\begin{array}{l}\text { Male } \\
(n=59)\end{array}$ & $\begin{array}{l}\text { Female } \\
(n=133)\end{array}$ & $\begin{array}{c}\text { Male } \\
(n=26)\end{array}$ & $\begin{array}{c}\text { Female } \\
(n=75)\end{array}$ & $\begin{array}{c}\text { Male } \\
(n=93)\end{array}$ & $\begin{array}{l}\text { Female } \\
(n=190)\end{array}$ & Male & Female & Male & Female \\
\hline Age, y & $65.83 \pm 4.84$ & $65.92 \pm 5.36$ & $66.50 \pm 4.55$ & $69.53 \pm 6.09$ & $68.45 \pm 5.63$ & $66.89 \pm 5.47$ & $p=0.015$ & $\mathrm{p}<0.001$ & $\begin{array}{l}\text { urban vs FELDA, } \\
p=0.015\end{array}$ & $\begin{array}{l}\text { urban vs rural, } \\
p<0.001 \\
\text { rural vs FELDA, } \\
p<0.001\end{array}$ \\
\hline \multicolumn{11}{|l|}{ Ethnicity } \\
\hline Malay & 15 & 30 & 26 & 75 & 93 & 190 & & & & \\
\hline Chinese & 34 & 85 & 0 & 0 & 0 & 0 & & & & \\
\hline Indians & 8 & 15 & 0 & 0 & 0 & 0 & & & & \\
\hline Others & 2 & 3 & 0 & 0 & 0 & 0 & & & & \\
\hline $\begin{array}{l}\text { Body mass } \\
\text { index, } \mathrm{kg} / \mathrm{m}^{2}\end{array}$ & $24.28 \pm 3.75$ & $24.30 \pm 4.52$ & $23.98 \pm 3.89$ & $25.34 \pm 4.86$ & $24.55 \pm 3.92$ & $26.89 \pm 5.24$ & $p=0.780$ & $\mathrm{p}<0.001$ & & $\begin{array}{l}\text { urban vs FELDA, } \\
\mathrm{p}<0.001\end{array}$ \\
\hline $\begin{array}{l}\text { Upper limb } \\
\text { strength, kg }\end{array}$ & $28.88 \pm 7.37$ & $18.50 \pm 5.85$ & $25.55 \pm 6.94$ & $15.87 \pm 4.24$ & $26.76 \pm 6.58$ & $18.14 \pm 5.14$ & $p=0.219$ & $\mathrm{p}=0.005$ & & $\begin{array}{l}\text { urban vs rural, } \\
\mathrm{p}<0.001 \\
\text { urban vs FELDA, } \\
\mathrm{p}=0.005 \\
\text { rural vs FELDA, } \\
\mathrm{p}=0.009\end{array}$ \\
\hline $\begin{array}{l}\text { Lower limb } \\
\text { strength, } \\
\text { repetitions }\end{array}$ & $14.26 \pm 4.72$ & $13.39 \pm 4.05$ & $12.90 \pm 4.14$ & $9.62 \pm 2.66$ & $11.79 \pm 3.56$ & $10.29 \pm 2.85$ & $p=0.004$ & $\mathrm{p}<0.001$ & $\begin{array}{l}\text { urban vs FELDA, } \\
\mathrm{p}=0.001\end{array}$ & $\begin{array}{l}\text { urban vs rural, } \\
p<0.001 \\
\text { urban vs FELDA, } \\
p<0.001\end{array}$ \\
\hline Mobility, s & $8.64 \pm 1.69$ & $9.79 \pm 2.81$ & $7.05 \pm 1.83$ & $10.03 \pm 9.09$ & $11.71 \pm 1.08$ & $11.64 \pm 1.87$ & $\mathrm{p}<0.001$ & $p=0.05$ & $\begin{array}{l}\text { urban vs rural, } \\
p=0.018 \\
\text { urban vs FELDA, } \\
p<0.001 \\
\text { rural vs FELDA, } \\
p<0.001\end{array}$ & $\begin{array}{l}\text { urban vs FELDA, } \\
p=0.001\end{array}$ \\
\hline
\end{tabular}

* Data are presented as mean \pm standard deviation or No. of participants

settlements were older than those living in FELDA settlements (69.53 vs 66.89, $\mathrm{p}<0.001$ ). In addition, women living in urban settlements had lower body mass index than did those living in FELDA settlements ( 24.30 vs 26.89 , $\mathrm{p}<0.001)$.

For upper limb strength, women living in rural settlements had lower handgrip strength than did those living in FELDA settlements (15.87 vs 18.14, $\mathrm{p}=0.009$ ) or urban settlements (15.87 vs 18.50, $\mathrm{p}<0.001)$ [T TABLE 1].

For lower limb strength, men living in urban settlements had more repetitions in the 30-second chair stand test than did those living in FELDA settlements (14.26 vs $11.79, \mathrm{p}=0.001)$; and women living in urban settlements had more repetitions than did those living in rural settlements (13.39 vs 9.62, $\mathrm{p}<0.001$ ) or FELDA settlements (13.39 vs 10.29, $\mathrm{p}<0.001$ ) [TABLE $\mathbf{1}$.
For mobility, men living in rural settlements were quicker in the timed up and go test than those living in urban settlements ( 7.05 vs $8.64, \mathrm{p}=0.001$ ) or FELDA settlements ( 7.05 vs $11.71, \mathrm{p}<0.001)$; and men living in urban settlements were quicker than those living in FELDA settlements (8.64 vs 11.71, $\mathrm{p}<0.001$ ). Women living in urban settlements were quicker in the timed up and go test than those living in FELDA settlements ( 9.79 vs 11.64, $\mathrm{p}=0.001$ ) [TABLE $\mathbf{1}$ ].

Mobility was correlated with upper limb strength in women living in urban settlements $(r=-0.408$, $\mathrm{p}=0.001)$, men living in rural settlements $(\mathrm{r}=-0.599$, $\mathrm{p}=0.003)$, and men living in FELDA settlements $(\mathrm{r}=-0.281, \mathrm{p}=0.006)$. Mobility was correlated with lower limb strength in women $(r=-0.686, p<0.001)$ and men $(r=-0.415, p=0.035)$ living in urban settlements, and women ( $r=-0.246, \mathrm{p}=0.001)$ and men $(\mathrm{r}=-0.281, \mathrm{p}=0.006)$ living in FELDA settlements [TABLE 2]. 


\section{DISCUSSION}

A study in Japan revealed that individuals living in rural areas had worse lower limb strength than those living in urban areas. ${ }^{13} \mathrm{~A}$ study of individuals living in FELDA settlements in Malaysia suggested that psychological factors were the main influence on health functioning. ${ }^{2}$ Similarly, another study of individuals living in FELDA settlements reported that low levels of mobility may contribute to depressive symptoms. ${ }^{9}$ The findings of the current study are consistent with these earlier studies, and indicate that mobility is an important component in geriatric assessment and may guide healthcare providers to design intervention that can promote physical independency.

The findings of the current study were inconsistent with a previous study, ${ }_{13}^{13}$ which found that individuals living in rural areas had better upper limb strength compared with those living in urban areas, but no significant difference in mobility between those living in urban or rural areas. Sampaio et $\mathrm{al}^{13}$ found that individuals living in urban areas had better lower limb strength than did those living in other areas, which is consistent with the findings of the current study.

Using upper limb strength as a key indicator for older adults at risk of sarcopenia, ${ }^{8}$ we found that men and women living in rural settlements and men living in FELDA settlements are at risk of sarcopenia. These findings are consistent with those of another study of older adults in western China that found that older adults living in rural areas are more vulnerable to sarcopenia than are those living in urban areas. ${ }^{14}$ In contrast, in a study of older women, Mazocco et $\mathrm{al}^{15}$ found that sarcopenia is more prevalent in those living in urban areas than in those living in rural areas.

TABLE 2

Correlations between mobility and upper and lower limb strength of older adults living in urban, rural, and Federal Land Development Authority (FELDA) settlements in Malaysia.

\begin{tabular}{|c|c|c|}
\hline \multirow[t]{2}{*}{ Variables } & \multicolumn{2}{|c|}{ Mobility } \\
\hline & $r$ & $p$ value \\
\hline \multicolumn{3}{|c|}{ Upper limb strength } \\
\hline \multicolumn{3}{|l|}{ Urban } \\
\hline Female & -0.408 & 0.001 \\
\hline Male & -0.180 & 0.379 \\
\hline \multicolumn{3}{|l|}{ Rural } \\
\hline Female & 0.036 & 0.777 \\
\hline Male & -0.599 & 0.003 \\
\hline \multicolumn{3}{|l|}{ FELDA } \\
\hline Female & -0.049 & 0.499 \\
\hline Male & -0.281 & 0.006 \\
\hline \multicolumn{3}{|c|}{ Lower limb strength } \\
\hline \multicolumn{3}{|l|}{ Urban } \\
\hline Female & -0.686 & $<0.001$ \\
\hline Male & -0.415 & 0.035 \\
\hline \multicolumn{3}{|l|}{ Rural } \\
\hline Female & -0.205 & 0.102 \\
\hline Male & -0.356 & 0.095 \\
\hline \multicolumn{3}{|l|}{ FELDA } \\
\hline Female & -0.246 & 0.001 \\
\hline Male & -0.281 & 0.006 \\
\hline
\end{tabular}


The differences found in the present study in strength and mobility among older adults from different settlements could be due to a few factors. Older adults living in urban and rural areas have significant differences in schooling, occupation, socioeconomic status, and smoking that may influence their quality of life. ${ }^{15}$ In addition, studies conducted in Malaysia have found that older adults residing in agricultural settlements are at malnutrition risk. ${ }^{16,17}$ The results of the current study show that mean body mass index was the highest for older men and women living in FELDA settlements, indicating that being overweight or obese may increase the risk of sarcopenia and the resulting vulnerability to diseases and physical decline.

Generally, in the current study, older adults living in urban settlements had better performance in almost all measured variables. Urban areas had a higher proportion of residents with Chinese ethnicity, whereas residents in rural and FELDA settlements were mostly of Malay ethnicity. A crosssectional study conducted in Malaysia found that, after controlling for age and sex, Chinese ethnicity and education level affected levels of total physical activity and moderate and vigorous exercise. ${ }^{18}$ Older adults living in urban areas may have a better awareness on the importance of regular exercise to keep fit and healthy owing to their higher level of education. Furthermore, more public recreational facilities such as walking pathways, gymnasiums, and parks are available in the urban areas. These facilities may motivate older adults to do more exercise outside their homes. Health services are also more accessible in urban areas compared with other settings.

In the current study, among older women living in urban areas, there are significant correlations between upper limb strength and mobility as well as between lower limb strength and mobility. In older men, significant correlations were found for upper limb strength for those living in urban and rural settlements, and lower limb strength was correlated with mobility in those living in urban and FELDA settlements. In a 1-year study, Yang et $\mathrm{al}^{19}$ found that good hand grip strength reduced the occurrence of falls among older men, indicating the importance of optimal strength for older adults in daily tasks such as preparing meals and walking.
There are some limitations to this study. We did not record information on comorbidities, smoking and drinking history, and socioeconomic status of the participants, and these factors may have influenced the levels of physical fitness of older adults. In addition, the number of participants and sex distributions were significantly different among the groups, and this could have affected the results. The low numbers of older men in each group could have contributed to the lack of significant findings, especially for upper and lower limb strength. The age and female body mass index of the three groups also differed significantly.

\section{CONCLUSION}

Older adults living in urban areas have better strength and mobility compared with those living in rural and FELDA settlements. The findings indicate that sociodemographic and cultural factors may affect strength and mobility of older adults. These findings provide knowledge for extensive study for the intervention and prevention of functional decline specific to the settlement of older adults in Malaysia. Further studies are recommended to determine whether the presence of comorbidities or socioeconomic status influence strength and mobility among older adults independent of residential settlement.

\section{DECLARATION}

The authors have no conflict of interest to disclose.

\section{REFERENCES}

1. Population and Demography. Department of Statistics Malaysia. Available at: https://www.dosm.gov.my/v1/index.php?r=column/ ctwoByCat\&parent_id=115\&menu_id=L0pheU43NWJwRWVS ZkIWdzQ4TlhUUT09. Accessed 23 March 2019.

2. Din NC, Ghazali SE, Ibrahim N, et al. Health needs assessment of older people in an agricultural plantation. Int J Gerontol 2014;8:120-6. Crossref

3. Chen L, Nelson DR, Zhao Y, Cui Z, Johnston JA. Relationship between muscle mass and muscle strength, and the impact of comorbidities: a population-based, cross-sectional study of older adults in the United States. BMC Geriatr 2013;13:74. Crossref

4. Cruz-Jentoft AJ, Baeyens JP, Bauer JM, et al. Sarcopenia: European consensus on definition and diagnosis: Report of the European Working Group on Sarcopenia in Older People. Age Ageing 2010;39:412-23. Crossref

5. Cruz-Jentoft AJ, Bahat G, Bauer J, et al. Sarcopenia: revised European consensus on definition and diagnosis, Age Ageing 2019;48:16-31. Crossref

6. Bellace JV, Healy D, Besser MP, Byron T, Hohman L.Validity of the 
Dexter Evaluation System's Jamar dynamometer attachment for assessment of hand grip strength in a normal population. J Hand Ther 2000;13:46-51. Crossref

7. Roberts HC, Denison HJ, Martin HJ, et al. A review of the measurement of grip strength in clinical and epidemiological studies: towards a standardised approach. Age Ageing 2011;40:423-9. Crossref

8. Chen LK, Liu LK, Woo J, et al. sarcopenia in Asia: consensus report of the Asian Working Group for Sarcopenia. J Am Med Dir Assoc 2014;15:95-101. Crossref

9. Jørgensen MG. Assessment of postural balance in communitydwelling older adults: methodological aspects and effects of biofeedback-based Nintendo Wii training. Dan Med J 2014;61:B4775

10. Jones CJ, Rikli RE, Beam WC. A 30-s chair-stand test as a measure of lower body strength in community-residing older adults. Res Q Exerc Sport 1999;70:113-9. Crossref

11. Shumway-Cook A, Brauer S, Woollacott M. Predicting the probability for falls in community-dwelling older adults using the Timed Up \& Go Test. Phys Ther 2000;80:896-903. Crossref

12. Faul F, Erdfelder E, Lang AG, Buchner A. G*Power 3: a flexible statistical power analysis program for the social, behavioral, and biomedical sciences. Behav Res Methods 2007;39:175-91. Crossref 13. Sampaio RAC, Sampaio PYS, Yamada M, Ogita M, Arai H.
Urban-rural differences in physical performance and health status among older Japanese community-dwelling women. J Clin Gerontol Geriatr 2012;3:127-31. Crossref

14. Gao L, Jiang J, Yang M, Hao Q, Luo L, Dong B. Prevalence of sarcopenia and associated factors in Chinese communitydwelling elderly: comparison between rural and urban areas. J Am Med Dir Assoc 2015;16:1003.e1-6. Crossref

15. Mazocco L, Gonzalez MC, Barbosa-Silva TG, Chagas P. Sarcopenia in Brazillian rural and urban elderly women: Is there any difference? Nutrition 2019;58:120-4. Crossref

16. Shahar S, Boon PC, Chan PP, Din NC. Malnutrition risk and its association with appetite, functional and psychosocial status among elderly Malays in an Agricultural settlement. Malays J Nutr 2013;19:65-75.

17. Zainudin N, Hamirudin AH, Rahman AN, Sidek S. Malnutrition risk and perception on dietary practices among elderly living in agricultural settlements: A mixed-methods research. Nutr Food Sci 2018:1-11.

18. Cai Lian T, Bonn G, Si Han Y, Chin ChooY, Chee Piau W. Physical activity and its correlates among adults in Malaysia: a crosssectional descriptive study. PLoS One 2016;11:e0157730. Crossref

19. Yang NP, Hsu NW, Lin $\mathrm{CH}$, et al. Relationship between muscle strength and fall episodes among the elderly: the Yilan study, Taiwan. BMC Geriatr 2018;18:90. Crossref 